\title{
Application of Spatial Information Grid System on Calculating Probability of Earthquakes Induced by Reservoir
}

\author{
Chunying $\mathrm{Yu}^{1}$, Zhiyong Chen $^{1}$, Qiuwen Zhang $^{2}$ \\ ${ }^{1}$ The 711th Spatial Information Research Institute, Guangzhou, China \\ ${ }^{2}$ Hubei Key Laboratory of Digital Watershed Science and Technology, HuaZhong University of Science and Technology, \\ Wuhan, China
}

\begin{abstract}
We introduced the Spatial Information Grid System(SIGS) into the research of reservoir-induced earthquakes based on simulated data and existing computational models. With the graphical and grid management functions, we calculated the probability of reservoir-induced earthquakes by dividing the study area into arbitrary size and shape on the SIGS platform.
\end{abstract}

Keywords-spatial information grid system; earthquakes induced by reservoir.

\section{INTRODUCTION}

Earthquakes induced by reservoirs are common environmental and geological problems in reservoir area. It is very necessary to predict the occurrence of earthquakes induced by reservoirs so as to establish the comprehensive system integrated by analysis forecast evaluation, security supervision warning and quakeproof anti-disaster decision. At the present stage, it is predicted that reservoirs induce earthquakes. It can quantize each environmental conditions and earthquake inducted by reservoirs by figuring out the existence of specific hydrological geological conditions in reservoir areas, select independent variables and dependent variables separately, establish function relations of both, establish forecast model to judge the possibility of earthquake induction so as to evaluate the earthquake location and highest possible strength ${ }^{[1][2]}$. The limitation of this method is that it can only make the prediction on the overall danger of earthquake induced by a reservoir, for the distribution of earthquake activities in reservoirs and surrounding areas is not homogeneous in space, so the danger cannot be predicted or evaluated in different locations and activity levels ${ }^{00} 0$.

SIGS divides targeted areas into regular or irregular ordered grid units in accordance with certain spatial sizes or resolution ratios, stores and analyzes data with the unit of grid, expresses analysis results and provides comprehensive data or special data for each type of users. SIGS uses the property of grid to describe the overall information in the range of grid units, implements Geographic Information System logic functions on the basis of dividing grids, which can solve the problem of heterogeneous spatial information area characteristics effectively, satisfy needs of different areas and different applications and provides new thinking for the management of spatial basic information.

We believe that it can introduce SIGS technology into the research of reservoir inducted earthquakes, divides research areas into several units in accordance with certain quantities of intervals, reservoir inducted earthquake is regarded as uniform inside every unit ${ }^{[2][3] \text {, }}$ which fully utilizes grid managing characteristics of SIGS and takes it as the basic data management platform of reservoir inducted earthquake research.

\section{THEORETICAL BASIS AND METHODOLOGY}

Research on special applications of SIGS in the aspect of reservoir inducted earthquake needs to select typical reservoirs and surrounding environments, utilizes SIGS spatial inquiry and browse and other database management functions as well as layer superposition, matching and other spatial comprehensive management and analysis functions and extracts environmental factor status values and earthquake activity level values related to inducted earthquakes.

On the basis of collecting and sorting out the general combination environmental conditions of each unit of inducted earthquake of reservoirs and surrounding areas, it uses SIGS to arrange grid management, inquiry, statistics and etc on environmental factor data of reservoir-inducted earthquake and calculates reservoir inducted earthquake prediction and parameters of evaluated models as well as possibilities inducting different activity levels. So far, Researchers such as Zhang Qiuwen, Li Anran, Yu Tinglin, Wang Cheng, Han Xiaoguang have done a vast amount of in-depth research on prediction and evaluation of reservoir-inducted earthquakes. The computing method and models mentioned in the paper are based on their achievements.

Argument of a function select formation lithology $(\mathrm{R})$, karst $(\mathrm{K})$, fracture $(\mathrm{F})$, $\operatorname{crack}(\mathrm{C})$, fractured reservoir loading $(\mathrm{W})$, the regional tectonic stress and the angle between the fault (A) as the dependent variable, in addition ,the function also put the quantization of each unit which induce earthquake activity level as variables.

The induced seismicity level can be divided into sporadic microseismic $\left(E_{1}\right)$, sporadic small earthquake $\left(E_{2}\right)$, frequent small earthquakes $\left(E_{3}\right)$ and destruct earthquakes or frequent, small earthquake $\left(E_{4}\right)$ and other 4 kinds of states ${ }^{[2][3][5]}$. The parameters needed to be calculated including different numbers of samples $\mathrm{N}_{\mathrm{i}}$ of inducing earthquake activity level $\left(\mathrm{E}_{\mathrm{i}}\right)$, various factors have different induced seismicity level in different condition $\left(E_{i}\right)$ samples with different $M_{i}$, different earthquake-induced activity level $\left(\mathrm{E}_{\mathrm{i}}\right)$ prior probability under $\mathrm{PE}_{\mathrm{i}}$, under various factors in different states, different earthquake-induced activity level $\left(E_{i}\right)$ of the conditional probability $\mathrm{PT}_{\mathrm{i}}^{[2]}$. 


$$
\begin{gathered}
P E_{i}=\frac{N_{i}}{\sum_{i=1}^{4} N_{i}} \\
P T_{i}=\frac{M_{i}}{N_{i}}
\end{gathered}
$$

$\mathrm{N}_{\mathrm{i}}$ is the sample size in different induced seismicity level $\left(E_{i}\right), M_{i}$ is the sample number in different level of seismic activity $\left(\mathrm{E}_{\mathrm{i}}\right)$.

According to the Bayes conditional probability theory, the induced geological environmental conditions of a certain unit which need to be evaluated is R, K, C, F, A, $\mathrm{W}$, the conditional probability $\mathrm{P}\left(\mathrm{E}_{\mathrm{i}} / \mathrm{R}, \mathrm{K}, \mathrm{C}, \mathrm{F}, \mathrm{A}, \mathrm{W}\right)$ of different levels of activity $\left(\mathrm{E}_{\mathrm{i}}\right)$ which induced by it can be calculated by formula ${ }^{[1][2] \text { : }}$

$$
\begin{gathered}
P\left(E_{i} / R, K, C, F, A, W\right)=\frac{P(i)}{P(5)} \\
P(i)=P E_{i} \times P\left(R, K, C, F, A, W / E_{i}\right) \\
P(5)=\sum_{i=1}^{4} P_{i}
\end{gathered}
$$

In the formula: $\mathrm{i}=1,2,3,4, \mathrm{PE}_{\mathrm{i}}$ is the prior probability when the seismic activity level is $\mathrm{E}_{\mathrm{i}}$; P (R, K, C, F, A, W $\left./ E_{i}\right)$ is the factors combined conditions probability when the level of seismic activity is $E_{i}$, by the calculation of formula ${ }^{[1][2]}$ :

$$
\begin{aligned}
& P(R, K, C, F, A, W)= \\
& P T_{i}(R) \times P T_{i}(K) \times P T_{i}(C) \times P T_{i}(F) \times P T_{i}(A) \times P T_{i}(W)
\end{aligned}
$$

In the formula: $\mathrm{PT}_{\mathrm{i}}(\mathrm{R}) 、 \mathrm{PT}_{\mathrm{i}}(\mathrm{K}) 、 \mathrm{PT}_{\mathrm{i}}(\mathrm{C}) 、 \mathrm{PT}_{\mathrm{i}}(\mathrm{F})$ 、 $\mathrm{PT}_{\mathrm{i}}(\mathrm{A})$ and $\mathrm{PT}_{\mathrm{i}}(\mathrm{W})$ are the combined conditions of event probability of parameter $R 、 K 、 C 、 F 、 A$ and $W$ when the level of the earthquake activity is $\mathrm{E}_{\mathrm{i}}$.

\section{APPLICATION EXAMPLES}

\section{A. Data Collection and Pre-treatment}

This article made a test for the head area of project library of the Changjiang River three gorges (E110.53 ${ }^{\circ}$ $\left.111.95^{\circ}, \mathrm{N} 30.88^{\circ}-30.91^{\circ}\right)$. For the convenience of study, in accordance with the $0.01 \times 0.01$ intervals, the area is divided into 1330 rules of unit ${ }^{[1][2][3]}$. According to the need of research, what is collected is the plane coordinates of center points of the 1330 units and reservoir and its each factor of reservoir earthquake affected by surrounding units, stored as XLS files (Figure 1) with Excel format, using the interface of SIGS to achieve the data conversion. What needs to be explained is that, the data in the form without investigation or observation can only be as a demonstration application of SIGS simulation data, prediction feasibility and evaluation model of reservoir earthquake-induced and therefore, according to the data calculation results calculated by the data are not used to support the decision-making of disaster relief.

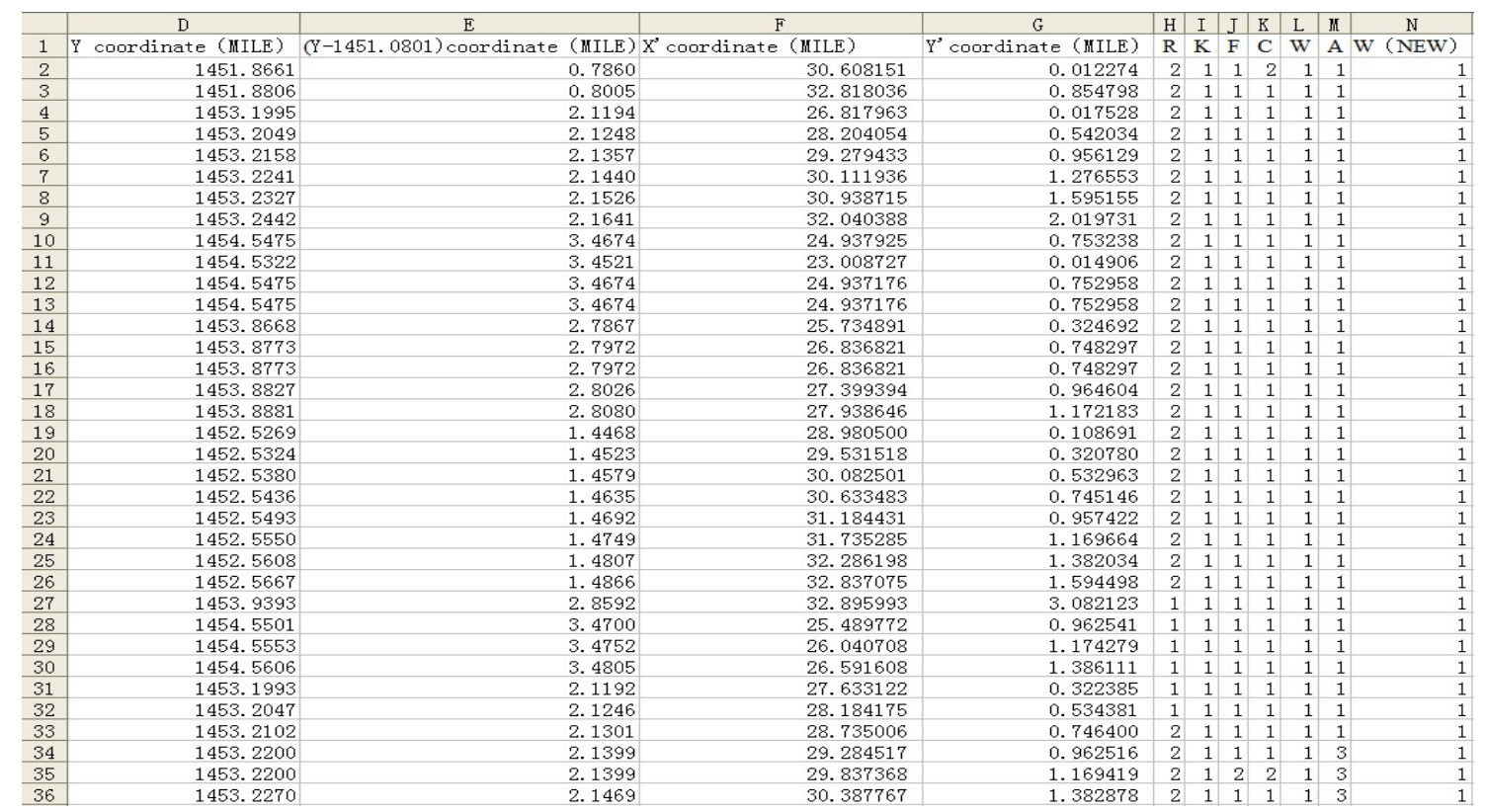

Figure 1. Central point plane coordinates of grid units and each factor status influencing reservoir earthquakes

\section{B. Data Read and Display}

By reading through the experimental data, it displays the data in the system with the form of point and grind, as it is shown in Fig.2., Fig.3. A few missing points are data unit with no corresponding coordinate, had no effect on the overall results. 


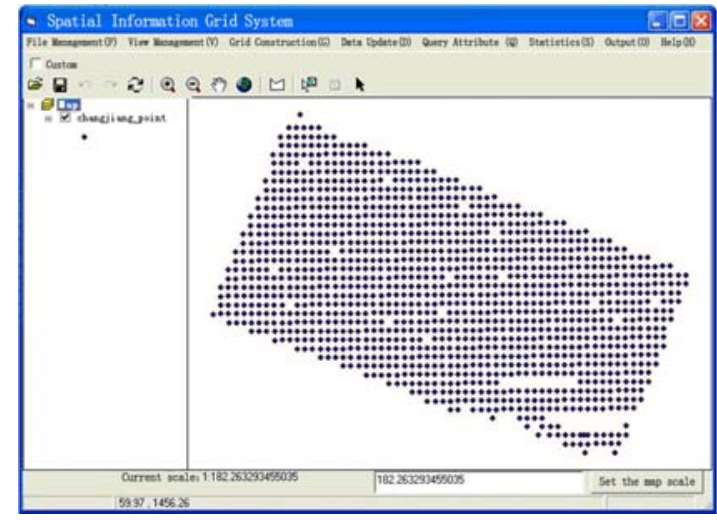

Figure 2. Data set displayed in point format

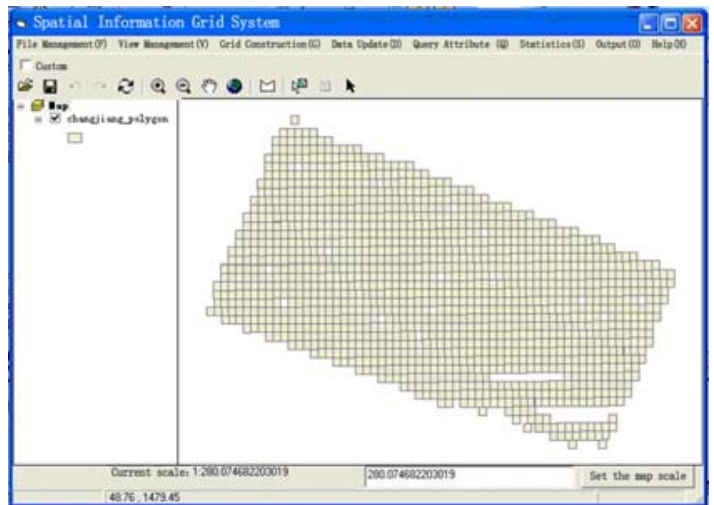

Figure 3. Data set displayed in grid format

\section{Sample number Ni Inquiry and Pre-test Possibility PEi Calculation}

$\mathrm{N}_{\mathrm{i}}$ can be obtained by property inquiry(Fig.4.), totally four values. Results are displayed in the status column of the main interface: "inquiring that 726 pieces", at the same time, grid units fitting " $E=1$ " condition are displayed in highlight (Fig.5.).

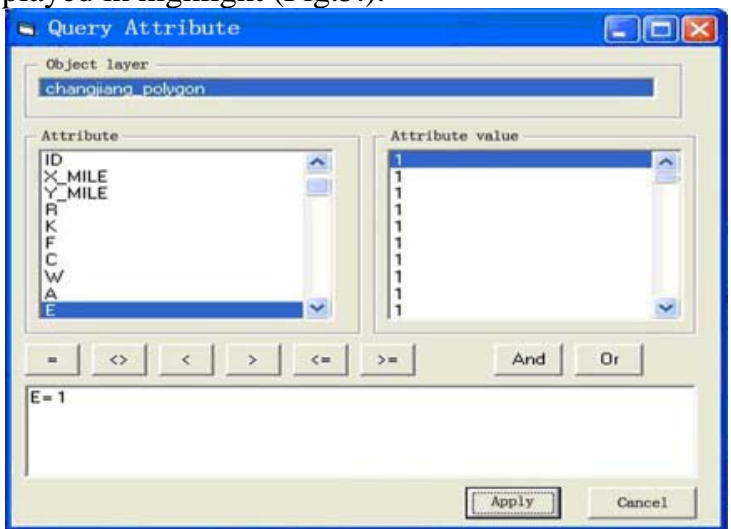

Figure 4. "Property inquiry”

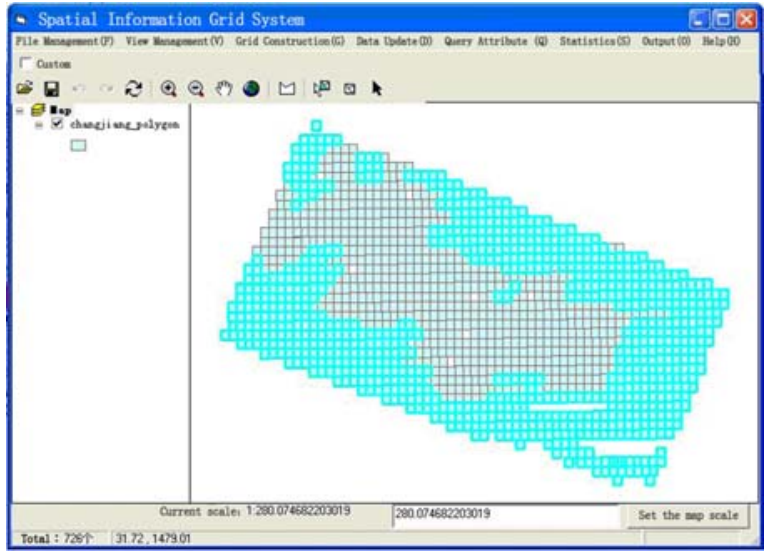

Figure 5.Inquiry of result output of " $\mathrm{E}=1$ "

Inquiry results of $\mathrm{N}_{\mathrm{i}}$ and possibility value $P E_{\mathrm{i}}$ are shown in tab.I.

TABLE I. SAMPLE NUMBER $\left(\mathrm{N}_{\mathrm{i}}\right)$ AND PRE-TEST POSSIBILITY $\left(\mathrm{PE}_{\mathrm{i}}\right)$ IN DIFFERENT EARTHQUAKE ACTIVITY LEVELS $\left(\mathrm{E}_{\mathrm{i}}\right)$

\begin{tabular}{|c|c|c|c|c|c|}
\hline \multirow{2}{*}{ Statistics } & \multicolumn{4}{|c|}{ Earthquake activity level } & \multirow{2}{*}{ Sum } \\
\cline { 2 - 5 } & $\begin{array}{c}\mathrm{E}_{1} \\
\mathrm{M}_{\mathrm{L}}<0.1\end{array}$ & $\begin{array}{c}\mathrm{E}_{2} \\
2.0 \geq \mathrm{M}_{\mathrm{L}} \geq 0.1\end{array}$ & $\begin{array}{c}\mathrm{E}_{3} \\
3.3 \geq \mathrm{M}_{\mathrm{L}}>2.0\end{array}$ & $\begin{array}{c}\mathrm{E}_{4} \\
5.5 \geq \mathrm{M}_{\mathrm{L}}>3.3\end{array}$ & \\
\hline $\begin{array}{c}\text { Sample } \\
\text { number } \mathrm{N}_{\mathrm{i}}\end{array}$ & 726 & 102 & 180 & 322 & 1330 \\
\hline $\begin{array}{c}\text { Possibility } \\
\text { value } \mathrm{PE}_{\mathrm{i}}\end{array}$ & 0.546 & 0.077 & 0.135 & 0.242 & 1.000 \\
\hline
\end{tabular}

$\mathrm{M}_{\mathrm{i}}$ is the number of sample with various factors has different induced seismicity level in different condition $\left(E_{i}\right) .1330$ grid unit state $(R, K, F, C, W, A)$ and earthquake-induced activity level (E) is not the same. To have Dynamic combined queries, we need to add some auxiliary fields to the table data in the calculation process which is used to store $\mathrm{M}_{\mathrm{i}}$, and participate in the subsequent calculation.

\section{Combination Condition Possibility PTi}

According to the formula (2), $\mathrm{PT}_{\mathrm{i}}$ is obtained by the $\mathrm{M}_{\mathrm{i}}$, and will serve as the model parameters are provided for the subsequent research, so need to add field named by "PEiR", "PEiK", "PEiF", "PEiC", "PEiW", "PEiA" ( $\mathrm{i}=1,2,3,4)$, type for Double, a total of 24, used to store $\mathrm{PT}_{\mathrm{i}}$.

After completing the calculation value of the field, find the factors of R corresponding to a state of NumEiR $\mathrm{M}_{\mathrm{i}}$, find $\mathrm{PEiR}$, get $\mathrm{PT}_{\mathrm{i}}$. Of course you can also query through the combination "E=i $(i=1,2,3,4)$ And $R=j(j=1$, $2,3,4)$ " to get $\mathrm{M}_{\mathrm{i}}$, using the formula (2) to calculate $\mathrm{PT}_{\mathrm{i}}$ (Tab.II.). 
TABLE II. COMBINATION CONDITION PROBABILITY (PT $\mathrm{i}$ ) OF EARTHQUAKES OF DIFFERENT ACTIVITY LEVELS INDUCTED BY EACH EARTHQUAKE FACTOR INDUCTS IN DIFFERENT STATUSES (i)

\begin{tabular}{|c|c|c|c|c|c|c|c|c|c|c|c|c|c|c|c|c|}
\hline \multirow{2}{*}{ Factor } & \multicolumn{8}{|c|}{ State 1} & \multicolumn{8}{|c|}{ State 2} \\
\hline & $\mathrm{M}_{1}$ & $\mathrm{M}_{2}$ & $\mathrm{M}_{3}$ & $\mathrm{M}_{4}$ & $\mathrm{PT}_{1}$ & $\mathrm{PT}_{2}$ & $\mathrm{PT}_{3}$ & $\mathrm{PT}_{4}$ & $\mathrm{M}_{1}$ & $\mathrm{M}_{2}$ & $\mathrm{M}_{3}$ & $\mathrm{M}_{4}$ & $\mathrm{PT}_{1}$ & $\mathrm{PT}_{2}$ & $\mathrm{PT}_{3}$ & $\mathrm{PT}_{4}$ \\
\hline $\mathrm{R}$ & 340 & 51 & 37 & 88 & 0.4683 & 0.5000 & 0.2056 & 0.2733 & 106 & 7 & 11 & 19 & 0.1460 & 0.0686 & 0.0611 & 0.0590 \\
\hline K & 482 & 61 & 63 & 118 & 0.6639 & 0.5980 & 0.3500 & 0.3665 & 101 & 20 & 47 & 95 & 0.1391 & 0.1961 & 0.2611 & 0.2950 \\
\hline$F$ & 483 & 33 & 81 & 127 & 0.6653 & 0.3235 & 0.4500 & 0.3944 & 127 & 27 & 35 & 74 & 0.1749 & 0.2647 & 0.1944 & 0.2298 \\
\hline C & 500 & 43 & 83 & 132 & 0.6887 & 0.4216 & 0.4611 & 0.4099 & 115 & 30 & 53 & 82 & 0.1584 & 0.2941 & 0.2944 & 0.2547 \\
\hline W & 627 & 8 & 54 & 15 & 0.8636 & 0.0784 & 0.3000 & 0.0466 & 55 & 75 & 28 & 38 & 0.0758 & 0.7353 & 0.1556 & 0.1180 \\
\hline A & 580 & 67 & 130 & 219 & 0.7989 & 0.6569 & 0.7222 & 0.6801 & 19 & 2 & 8 & 23 & 0.0262 & 0.0196 & 0.0444 & 0.0714 \\
\hline \multirow{2}{*}{ Factor } & \multicolumn{8}{|c|}{ State 3} & \multicolumn{8}{|c|}{ State 4} \\
\hline & $\mathrm{M}_{1}$ & $\mathrm{M}_{2}$ & $\mathrm{M}_{3}$ & $\mathrm{M}_{4}$ & $\mathrm{PT}_{1}$ & $\mathrm{PT}_{2}$ & $\mathrm{PT}_{3}$ & $\mathrm{PT}_{4}$ & $\mathrm{M}_{1}$ & $\mathrm{M}_{2}$ & $\mathrm{M}_{3}$ & $\mathrm{M}_{4}$ & $\mathrm{PT}_{1}$ & $\mathrm{PT}_{2}$ & $\mathrm{PT}_{3}$ & $\mathrm{PT}_{4}$ \\
\hline $\mathrm{R}$ & 84 & 19 & 64 & 113 & 0.1157 & 0.1863 & 0.3556 & 0.3509 & 196 & 25 & 68 & 102 & 0.2700 & 0.2451 & 0.3778 & 0.3168 \\
\hline $\mathrm{K}$ & 110 & 12 & 44 & 75 & 0.1515 & 0.1176 & 0.2444 & 0.2329 & 33 & 9 & 26 & 34 & 0.0455 & 0.0882 & 0.1444 & 0.1056 \\
\hline $\mathrm{F}$ & 94 & 33 & 44 & 70 & 0.1295 & 0.3235 & 0.2444 & 0.2174 & 22 & 9 & 20 & 51 & 0.0303 & 0.0882 & 0.1111 & 0.1584 \\
\hline C & 75 & 14 & 23 & 54 & 0.1033 & 0.1373 & 0.1278 & 0.1677 & 36 & 15 & 21 & 54 & 0.0496 & 0.1471 & 0.1167 & 0.1677 \\
\hline W & 23 & 0 & 94 & 57 & 0.0317 & 0 & 0.5222 & 0.1770 & 21 & 19 & 4 & 212 & 0.0289 & 0.1863 & 0.0222 & 0.6584 \\
\hline A & 34 & 3 & 4 & 23 & 0.0468 & 0.0291 & 0.0222 & 0.0714 & 93 & 30 & 38 & 57 & 0.1281 & 0.2941 & 0.2111 & 0.1770 \\
\hline
\end{tabular}




\section{E. Condition Possibility P (Ei/R, K, C, F, A, W)}

After using of the SIGS to get combined conditional probability $\mathrm{PT}_{\mathrm{i}}$ from table 2 , conditional probability $\mathrm{P}$ $\left(\mathrm{E}_{\mathrm{i}} / \mathrm{R}, \mathrm{K}, \mathrm{C}, \mathrm{F}, \mathrm{A}, \mathrm{W}\right)$ induced by different levels of activity $\left(E_{i}\right)$, can calculate by using formula (1) (5),here the method is not narrate again.

\section{F. Calculation of PEi}

The 1330 grid cells engaged in the reservoir-induced earthquake predicting model parameter calculation could be also regard as evaluated units to calculate the probability of recurrence of 4 kinds of induced earthquakes in the unit. We could achieve that by creating new fields "PE1", "PE2", "PE3" and "PE4" in the "calculation" dialog, selecting the evaluate field, inputting the calculation formula and clicking the "calculation" button. The above added fields and calculation can be batch processed by code.

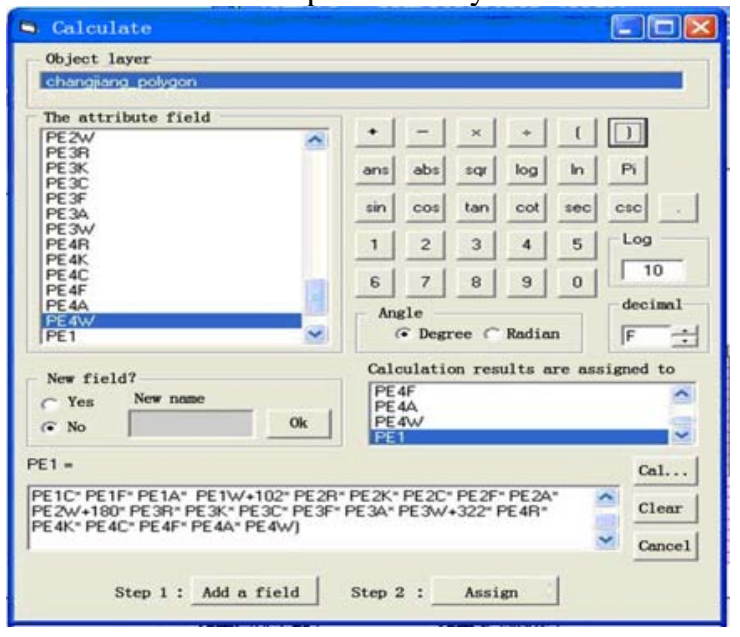

Figure 6. Calculation of PE1

\section{G. Output}

To get an easy approach to the result, we can use the "statistics" function to output PEi as Fig. 7. shows. We can also display the probability of every unit simultaneously in the plot window (Fig.8.).

\begin{tabular}{|c|c|c|c|c|c|c|c|c|}
\hline $100 x$ & 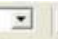 & $14+1$ & & 1 ¿ $18+$ & , & $1=$ & $\mathbf{M}$ & crystal $0^{\circ}$ \\
\hline & & & & \multicolumn{5}{|c|}{ Induced Earthquake Probability of Each Unit } \\
\hline & 10 & & E & PE1 & $P E 2$ & PE: & & PE4 \\
\hline & 1 & & 1 & 0.97 & 0.00 & 0.02 & & 0.00 \\
\hline & 2 & & 1 & 0.99 & 0.00 & 0.01 & & 0.00 \\
\hline & 3 & & 1 & 0.99 & 0.00 & 0.01 & & 0.00 \\
\hline & 4 & & 1 & 0.99 & 0.00 & 0.01 & & 0.00 \\
\hline & 5 & & 1 & 0.99 & 0.00 & 0.01 & & 0.00 \\
\hline & 6 & & 1 & 0.99 & 0.00 & 0.01 & & 0.00 \\
\hline & 7 & & 1 & 0.99 & 0.00 & 0.01 & & 0.00 \\
\hline & 8 & & 1 & 0.99 & 0.00 & 0.01 & & 0.00 \\
\hline & 9 & & 1 & 0.99 & 0.00 & 0.01 & & 0.00 \\
\hline & 10 & & 1 & 0.99 & 0.00 & 0.01 & & 0.00 \\
\hline & 11 & & 1 & 0.99 & 0.00 & 0.01 & & 0.00 \\
\hline 6 & 12 & & 1 & 0.99 & 0.00 & 0.01 & & 0.00 \\
\hline
\end{tabular}

Figure 7. Report preview
We applied SIGS system to the experimental data of various influence factors of reservoir earthquake from the front area of project library of the Changjiang River three gorges and its peripheral units and worked out the probability of reservoir-induced earthquakes. We can indicate from the result that every unit has the highest probability of sporadic microquake while having relatively low probability of strong destructive earthquake or frequently Small earthquake.

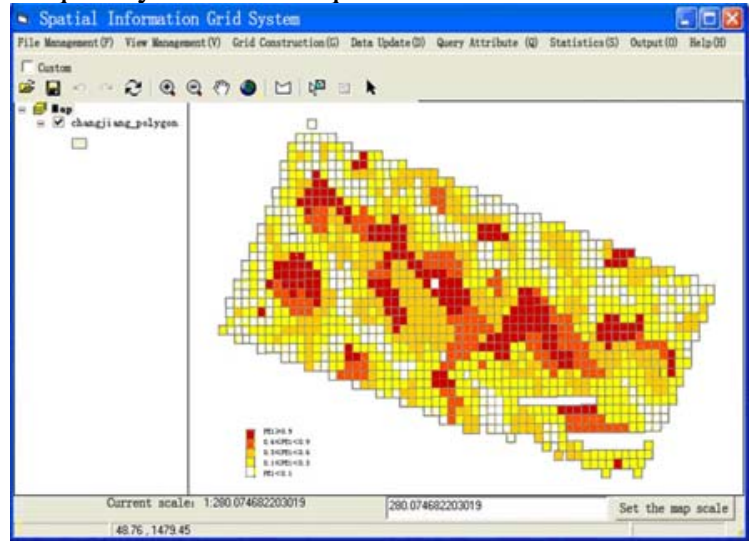

Figure 8 . The probability of sporadic microquake( PE1)

\section{CONCLUSION}

With the graphical and grid management functions of the SIGS, we calculated the probability of reservoir-induced earthquakes by dividing the study area into arbitrary size and shape while calculating every unit and comparing the results simultaneously. The system can offer visualized result, user-friendly operation and good practicability. Besides the regular shape mesh employed in this study, the system also offers irregular shape mesh for the user. In actual applications, if adopting the data with actual investigation or observation, calculation results can be referenced by related departments.

\section{REFERENCES}

[1] Zhang Qiuwen, Wang Cheng, Li Feng. Three Gorges Head Area and Surrounding Area Reservoir Inducted Earthquake Hazard Quantitative Prediction and Evaluation Research [J]. Hydroelectric Power Science, 23(4), pp. 21-25, 2005.

[2] Zhang Qiuwen, Wang Cheng, Li Anran and etc. Research on Small Division of Inducted Earthquake Hazard in Hydraulic and Hydro-Power Engineering and its Surrounding Areas [J]. Rock Mechanics and Engineering Journal, 23(17), pp. 2925-2931, 2004.

[3] Zhang Qiuwen, Li Anran, Wang Qingyun and etc, A Model and its Applications of Evaluation on Inducted Earthquake Hazard in Reservoirs and Surrounding Areas [J]. Earthquake Geology, 20(4), pp. 361-369, 1998.

[4] Denlinger R P, Bufe J M. Reservoir conditions related to induced seismicity at the Geysers steam reservoir,northern California[J]. Bull Seismol Soc Am, 72, pp. 1317-1327, 1982.

[5] Li Anran, Han Xiaoguang, Xu Yongjian. Primary Exploration on Formation Mechanisms and Inciting Environment of Reservoir Earthquakes [J]. Southern China Earthquake, 7(2), pp. 81-89, 1987. 